\title{
A survey on the influence of intense rainfall induced by climate warming on operation safety and service life of urban asphalt pavement
}

\author{
Wentao Wang ${ }^{1}$, Linbing Wang ${ }^{2,3^{*}}$, Yinghao Miao ${ }^{1}$, Chunru Cheng ${ }^{1}$ and Shiwu Chen ${ }^{1}$
}

\begin{abstract}
Intense rainfall induced by climate warming is causing more common extreme meteorological events such as urban waterlogging in recent years. The urban waterlogging often has a wide-ranged severe impact on urban traffic. General intense rainfall weather makes urban transportation frequently be served in an environment with abundant water, which not only affects its operation safety but also challenges the service life of urban asphalt pavement. This paper presents a comprehensive survey on the influence of intense rainfall on urban transportation. The characteristics of meteorological phenomena such as climate warming, intense typhoon and rainfall, and urban waterlogging are firstly discussed. Then, Shenzhen, the city in south China, is chosen to analyze its historical meteorological variation in recent years, which was recently affected by a typhoon name Ewiniar in 2018 and caused severe waterlogging throughout entire city. Further, the operation safety of urban traffic is investigated with an increasing depth of surface runoff in intense rainfall weather, followed by the service life of asphalt pavement related to the moisture damage induced by dynamic pore water pressure. Finally, a series of measures to alleviate the effects of intense rainfall induced by climate warming on urban waterlogging and long service life of asphalt pavement are recommended.
\end{abstract}

Keywords: Climate warming, Intense rainfall, Urban waterlogging, Surface runoff, Aquaplaning, Moisture damage

\section{Introduction}

Global climate warming is a fact that has been widely recognized and accepted by various countries in the world, while a series of climatic disasters caused by the global climate warming is the reality that human has to face. The occurrence of tropical cyclones and typhoons become more frequent in recent years [1], which often accompanied by extreme heavy precipitation. The intense rainfall weather shows an increasing occurrence in cities. When the drainage capacity of urban underground drainage system does not match the precipitation

\footnotetext{
*Correspondence: wangl@vt.edu

${ }^{2}$ Joint USTB-Virginia Tech Lab on Multifunctional Materials, USTB, Beijing 100083, China

${ }^{3}$ Virginia Tech, Blacksburg, VA 24061, USA

Full list of author information is available at the end of the article
}

accumulation, it often results in severe urban waterlogging. Many cities have experienced waterlogging, such as Beijing [2] and Wuhan [3] in China, Atlanta [4] and Chicago [5] in the United State, and so on. The Chinese government conducted a survey on the detailed number of cities that had experienced urban waterlogging during 2008 to 2010 [6]. Among 351 cities of 32 provinces in China, urban waterlogging occurred in $62 \%$ samples and 137 cities even experienced more than three times during such period. Further, $78.9 \%$ samples had the flood period longer than $0.5 \mathrm{~h}$ and 57 cities of which even longer than $12 \mathrm{~h}$, while the flooded water depths of $74.6 \%$ samples were larger than $50 \mathrm{~mm}$. As shown in Fig. 1, a severe urban waterlogging occurred in Guangdong Province of China in 2018 caused huge damage to cities. The 


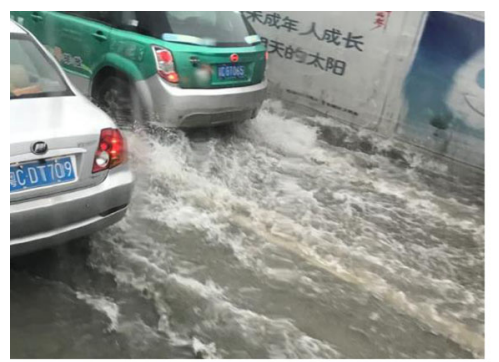

(a) Low traffic operational efficiency

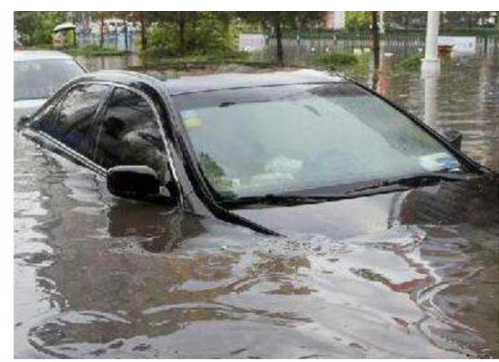

(b) Vehicles immersed in water

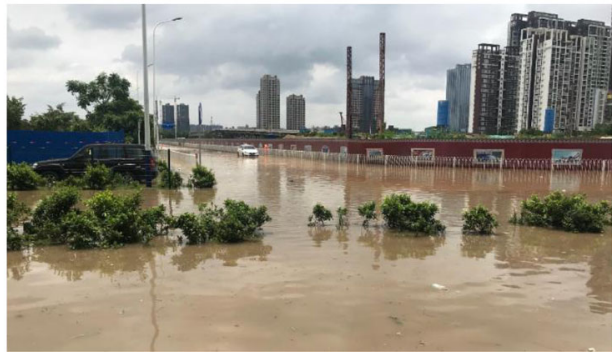

(c) Muddy water pollution

Fig. 1 Urban waterlogging caused by intense rainfall in Guangdong Province

increasing frequency of urban waterlogging induced by extreme intense rainfall greatly affects the normal operation of urban traffic and deteriorates the performance of urban asphalt pavement.

For common intense rainfall weather, the increase in its frequent occurrence and precipitation intensity will affect the operation safety and service life of urban asphalt pavement. The increasing thickness of surface runoff on asphalt pavement induced by intense rainfall undoubtedly causes greater safety risks to driving. Besides, the multi-field coupled dynamic response of saturated asphalt pavement under vehicle loading impacts its service life [7]. The repeated interaction between vehicle tires and asphalt pavement with surface runoff often generates dynamic pore water pressure. This kind of water environment exhibits a different damage mechanism on asphalt materials compared with static water immersion and freeze-thaw environments [8,9]. A field survey was conducted in 2012 on the service conditions of surface asphalt pavement for a highway with a length of $135 \mathrm{~km}$ [8]. The highway is located in Hubei Province of China and serves in a typical environment of high temperature and rich rainfall in summer. It was found that the main distress of asphalt pavement surface layer in this highway was moisture damage and mainly in form of raveling with pumping phenomenon, which accounted for $87.9 \%$ of total distresses. The conclusion of the field survey is one of the evidences to show the obvious influence of moisture damage concerning dynamic pore water pressure on service status for asphalt pavement. In this case, it's inaccurate to predict the service life of asphalt pavement to evaluate moisture damage resistance of asphalt mixture without taking into account of the action effect of dynamic pore water pressure. Moreover, the frequent occurrence of intense rainfall induced by climate warming aggravates the influence of dynamic pore water pressure on moisture damage, which increases the adverse effect of water on service life of asphalt pavement.

The objective of this study is to investigate the influence of intense rainfall induced by climate warming on urban asphalt pavement. Firstly, the characteristics of meteorological phenomena such as climate warming, intense typhoon and rainfall, and urban waterlogging are analyzed. Specially, the city of Shenzhen in south China is chosen to analyze its meteorological variation on the basis of historical data in recent years. Further, the impacts of intense rainfall on operation safety and service life of urban asphalt pavement are comprehensively discussed. Finally, a series of effective measures to mitigate the impacts of intense rainfall are proposed. The framework of this paper is shown in Fig. 2.

\section{Characterization of meteorological phenomena induced by climate warming} Climate warming

The increasing frequent occurrence of extreme climatic weather such as typhoon, intense rainfall and urban waterlogging in recent years is closely related to climate warming. The greenhouse gas emissions caused by fossil energy consumption are considered to be the main reason of global climate warming [10]. Figure 3 (a) shows temperature anomaly fluctuations of the past 139 years for global land and sea surface based on global average 


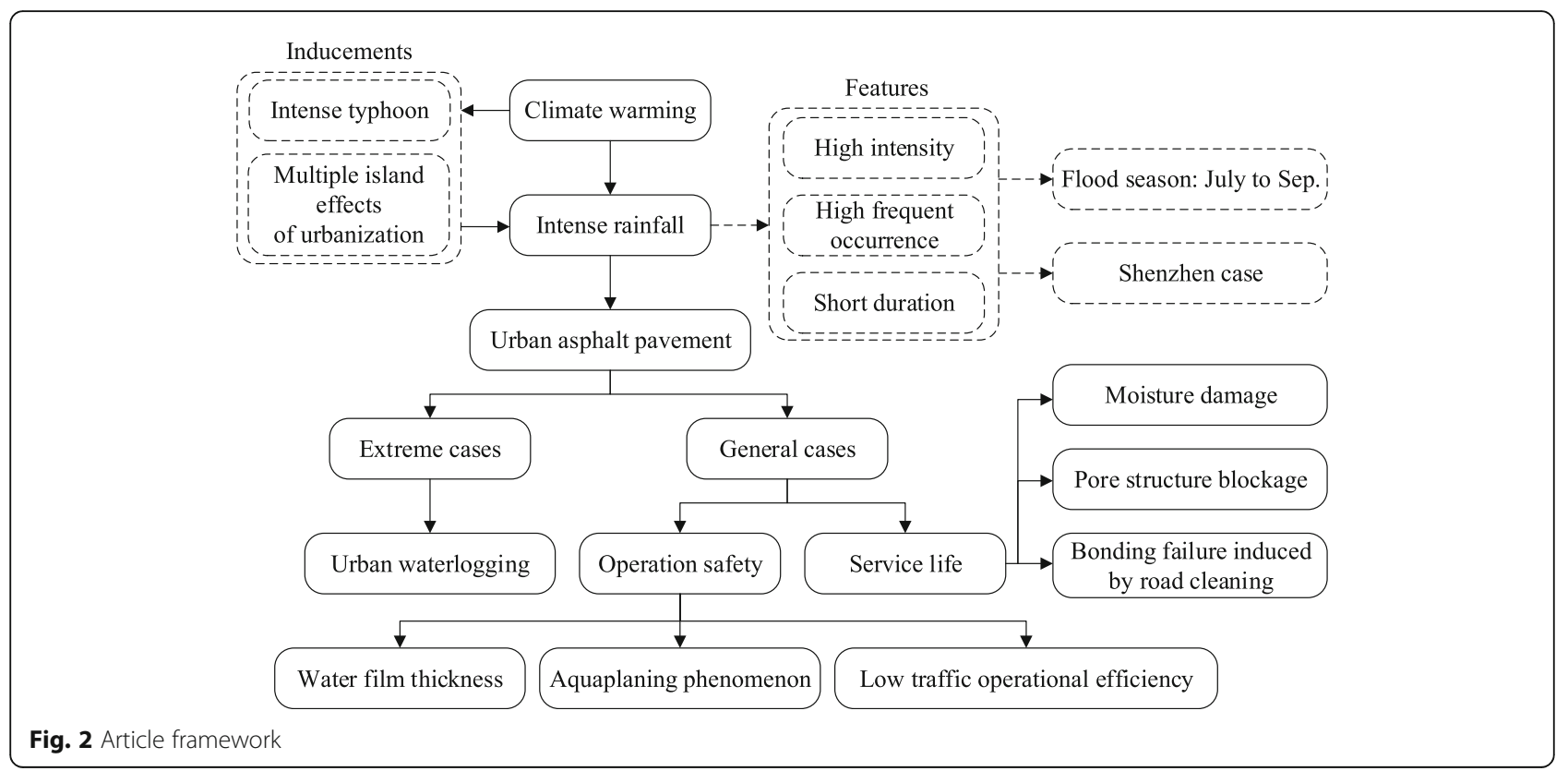

annual temperature from 1901 to 2000 [11]. It comes to the conclusion that global temperature has obviously and rapidly increased in the later period of social modernization process. The global average temperature in 2019 has increased by $0.95^{\circ} \mathrm{C}$ and years of 2015 to 2019 are the five consecutive warmest years in the past 139 years. The temperature anomalies of central Shenzhen district are shown in Fig. 3 (b), which is located in $22.66^{\circ} \mathrm{N}$ and $114.20^{\circ} \mathrm{E}$. It can be found that climate warming mainly occurred in the 1990s and gradually increased with the implementation of reform and openingup policy in China. The year of 2019 is the warmest year in Shenzhen which increased by $0.89^{\circ} \mathrm{C}$. The temperature anomaly fluctuations in central Shenzhen district basically shown consistent tendency with that of global land and sea surface.

\section{Intense typhoon}

Sea surface temperature is one of important influential factors on typhoon formation. Higher sea surface temperature is related to the increased water vapor in the lower troposphere. The total amount of water vapor over the global oceans has increased by $1.3 \pm 0.3 \%$ per decade since 1988 [12]. Both higher sea surface temperature and increased water vapor tend to increase the atmospheric convective available potential energy (CAPE) [13], which promotes the formation of thunderstorm and gradually develop into tropical cyclones and typhoons. Emanuel [14] evaluated the destructiveness of tropical cyclones since 1950 using the indicator of power dissipation index (PDI). The PDI was defined as the integral of the total power dissipation of tropical cyclone over its lifetime. It was found that the PDI indicator showed an increasing tendency since mid-1970s, which was basically the same as the tropical sea surface temperature. Kanada et al. [15] used four $5-\mathrm{km}$ mesh models to numerically investigate typhoons' changes between years of 1979-2003 and 2079-2099. The characteristics of sudden changes in precipitation and nearsurface wind speeds were found to be appeared around the storm center of future typhoons. Yamada et al. [16] also simulated future changes in tropical cyclone activity and structure using a 14- $\mathrm{km}$ mesh climate model, while numerical outputs between years of 1979-2008 and 2075-2104 were compared. In the future background of global climate warming, the occurrence frequency of tropical cyclones was found to be reduced by $22.7 \%$, but intense tropical cyclones increased by $6.6 \%$ and the precipitation rate within $100 \mathrm{~km}$ of the tropical cyclone center increased by $11.8 \%$. Therefore, the global climate warming will lead to an upward trend in tropical cyclone destructive potential, which also accompanies by an increasing occurrence frequency of intense rainfall weather.

\section{Intense rainfall}

The intensity of rainfall process can be distinguished by the indicator of daily precipitation (DP). The ranges of DP for rainstorm and large rainstorm are $50-100 \mathrm{~mm}$ and $100-200 \mathrm{~mm}$, respectively, while extraordinary rainstorm has a DP larger than $200 \mathrm{~mm}$ [17]. In this study, intense rainfall collectively refers to rainstorm, large rainstorm and extraordinary rainstorm, while the extraordinary one often appears in extreme weather of typhoon. Both global climate warming and urbanization significantly increase the frequency of heavy rainfall 


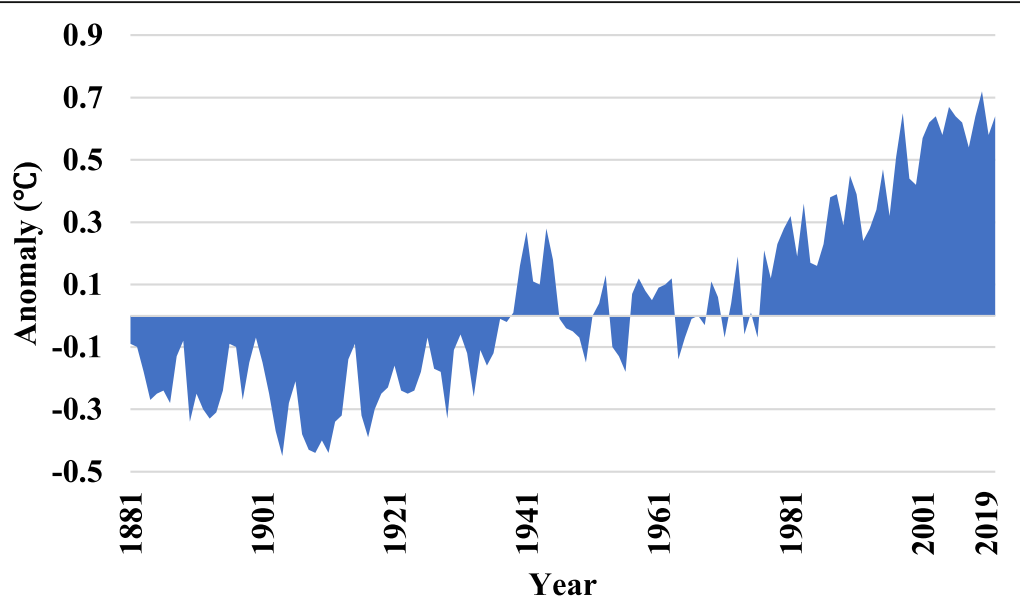

(a) Global land and sea surface

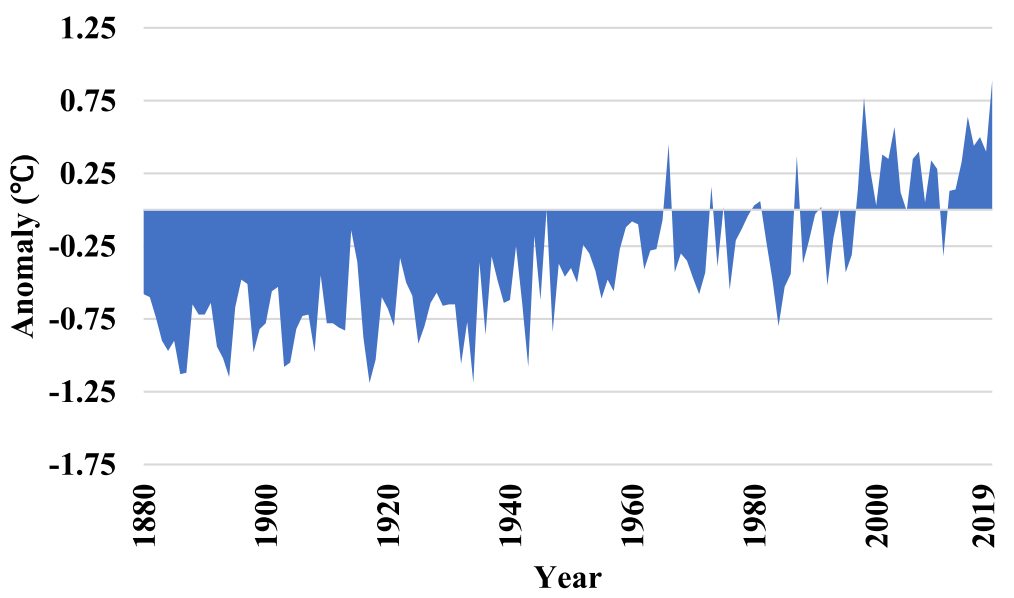

(b) Central Shenzhen district

Fig. 3 Annual temperature anomalies (1881-2019) [11]

events [18]. Chen et al. [19] analyzed relationships between rainfall intensities and mean temperatures using the Mann-Kendall trend test method for nine sites in eastern Australia. It was found that changes in rainfall intensity at short duration (less than $1 \mathrm{~h}$ ) positively correlated with changes in the mean maximum temperature. Trenberth et al. [20] found that rainfall intensity increased by $7 \%$ when climate temperature increased $1{ }^{\circ} \mathrm{C}$. Chen [21] statistically analyzed the variation between rainfall intensity and factors of temperature and cloud condensation nuclei for four cities in Guangdong Province. It was found that three rainfall intensities increased larger than $10 \%$ and the rest was raised even up to $24 \%$ when atmosphere temperature increased $1{ }^{\circ} \mathrm{C}$.

Regional climate change has become more obvious due to the rapid development of urbanization, which is conducive to the formation of multiple urban island effects. A schematic diagram of multiple effects of urbanization on precipitation is shown in Fig. 4. The rising temperature of land surface induced by climate warming accelerates the evaporation of surface water [12], which forms a large amount of water vapor in the lower atmosphere and provides favorable conditions for the formation of rainstorm. The concentration of urban high-rise buildings decreases wind speed and blocks air circulation, which results in a long residence time of water vapor [22]. Vehicle exhaust and air conditioning refrigeration increase heat emissions. Nie et al. [23] simulated the influence of anthropogenic heat emissions on urban rainfall for four short rainfall events in Beijing, while anthropogenic heat was found to obviously increase rainfall intensity over the urban area. Particulate matter and dust exhausted from factories and vehicles 


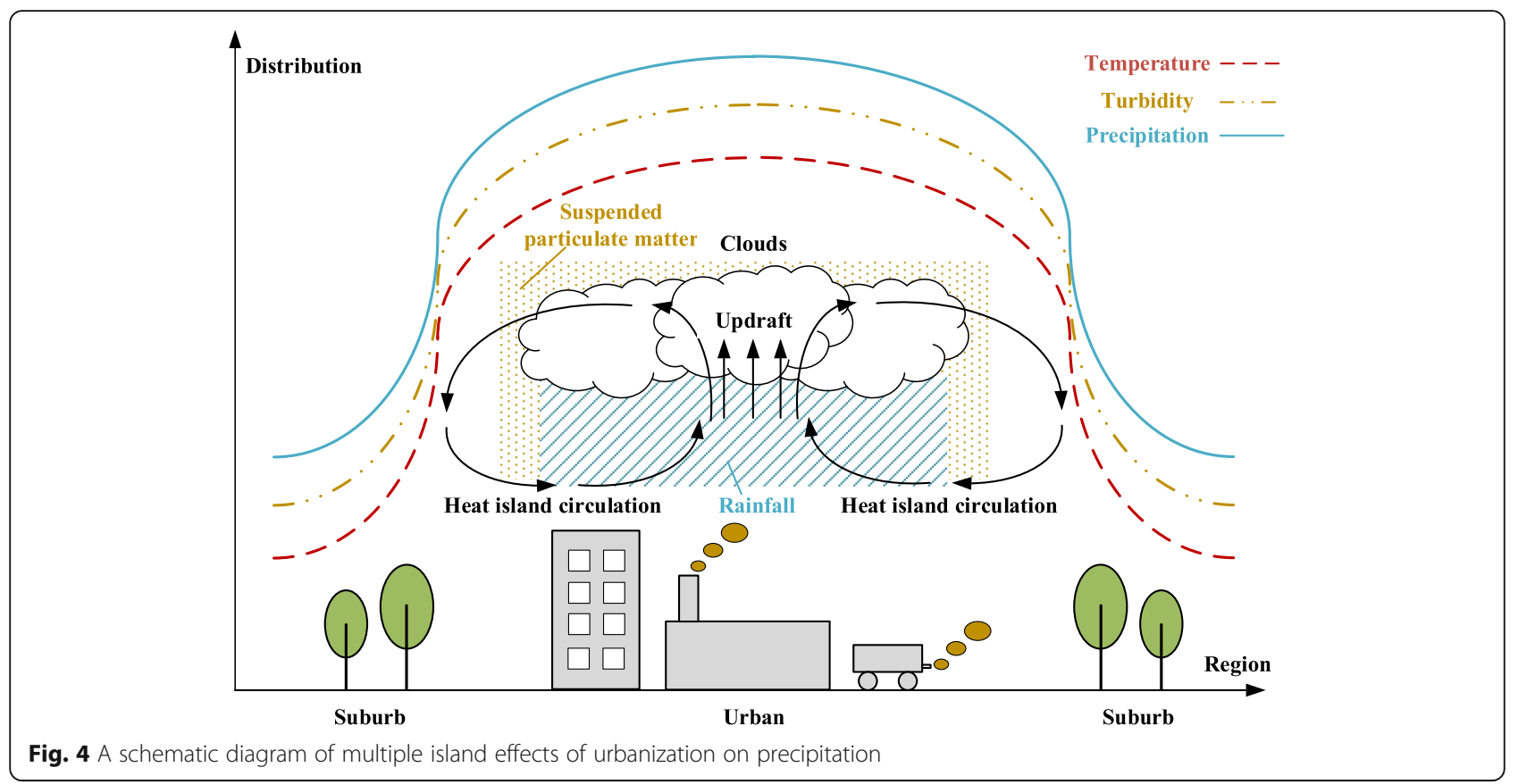

make the air turbidity degree of central cites larger than surrounding districts. These factors make distribution degrees of heat, turbidity and water vapor in central urban larger than surrounding suburb districts, both of which create favorable conditions for the formation of urban intense rainfall [24].

The rainfall distribution in each month within a year is not uniform. Annual period from June to September is usually called as flood season, which has a relative high occurrence frequency of hydrological and meteorological disasters. Fang et al. [25] analyzed rainfall characteristics in Shanghai over nearly 40 years, and it was found that almost $60 \%$ of the heavy rain and $84 \%$ of the rainstorm throughout 1 year were concentratedly occurred in flood season, especially in August. The average annual rainfall intensity in Shanghai increased at a rate of $50.9 \mathrm{~mm}$ per 10 years, but the number of rain days significantly decreased at a rate of 3 days per 10 years [25]. Frich et al. [26] proposed ten indicators to monitor change in climatic extremes world-wide. It was found that the world has become both warmer and wetter, while heavy rainfall events would become more frequent in the future. Most disastrous intense rainfall, which are usually caused by typhoons, have the characteristics of high rainfall intensity, high frequent occurrence, short duration $[27,28]$, while the resulting disaster of urban waterlogging often has a wide-ranged severe impact.

\section{Urban waterlogging}

Urban waterlogging refers to the phenomenon that precipitation accumulation of continuous intense rainfall exceeds the drainage capacity of urban drainage systems and finally results in water flooding disasters in cities. The intense rainfall induced by climate change and extreme weather event is the direct inducement of urban waterlogging. Besides, the urban rapid development impacted on urban water systems in several aspects such as the reduction of river flood discharge capacity and rainwater storage capacity, the destruction of water circulation system, and the changes of surface runoff [6], all of which also greatly affected the formation of urban waterlogging. The destructive behaviors that turn lake and river regions into hardening roads and buildings by urbanization process greatly reduce the flood storage capacity of these regions. Gao et al. [3] analyzed the distribution of lakes in Wuhan, while it was found that 89 lakes were disappeared and one third lake area was reduced after 20 years of urbanization, which was thought to be one of main inducements for frequent urban waterlogging in Wuhan. The lagging urban rainwater pipe network and the reducing greenbelt vegetation coverage are non-negligible factors related to urban waterlogging. The surface runoff coefficient in Shenzhen increased by 32\% from 1980 to 2015 [29], which meant an increased amount of rainfall flow and greatly burdened the urban drainage system. Chapman et al. [30] numerically analyzed the impact of vegetation cover loss on the heat island effect in a subtropical city of Australia. It was found that no vegetation cover made the mean maximum increase in urban temperature up to $3.8^{\circ} \mathrm{C}$ during a widespread extreme heat events, which was considered being beneficial for urban rainfall formation. 
Urban geographic information with high precision is often used to quantitatively evaluate severity of urban waterlogging [31]. Sun [32] statistically analyzed historical data of waterlogging and land use of central Beijing district. It was found that the river network density and the average slope of urban land surface were linearly positively correlated with urban waterlogging degree, while vegetation cover ratio showed a linear negative correlation. Zhang et al. [33] proposed the criteria and classification to quantitatively evaluate urban waterlogging, as shown in Table 1 . Only three criteria of depth, scope and period were met simultaneously could the stagnant water be defined as urban waterlogging. Li et al. [34] simulated the dynamic diffusion of pluvial flash flood in the traffic network in Shanghai and evaluated its influence on transportation for the commuting group. It was found that the travel demand in a rainstorm and flood weather would be reduced by $20 \%$, while vehicles trapped in severely flooded regions would be delayed at least one to $3 \mathrm{~h}$.

\section{Analysis of Shenzhen case}

Shenzhen, which is located on the southern coast of Guangdong Province in China, has a subtropical marine climate. The typhoon named Ewiniar landed Shenzhen in June 2018 and caused three consecutive days of intense rainfall with a citywide wind of level seven [1]. The maximum and mean DPs were $318.3 \mathrm{~mm}$ and $260.7 \mathrm{~mm}$, respectively, both of which reached the level of extraordinary rainstorm. Water accumulated in 226 places throughout the city, most of which had water depths of $30-50 \mathrm{~cm}$, while some were $70-100 \mathrm{~cm}$ and the extreme maximum water depth could reach $1.5 \mathrm{~m}$. The severe waterlogging greatly impacted the traffic throughout the entire city. The severity of intense rainfall regions is highly related with the typhoon's track. The mean DP distribution at the distance of $500 \mathrm{~km}$ from typhoon center can decrease exponentially by $80 \%$ compared with that at the distance of $100 \mathrm{~km} \mathrm{[35].} \mathrm{There} \mathrm{were} \mathrm{eight} \mathrm{ty-}$ phoons in total entered the $500 \mathrm{~km}$ range circle of Shenzhen in 2018, while four of which obviously affected meteorology of Shenzhen. The track of Ewiniar almost reached the $100 \mathrm{~km}$ range circle and was closer to the central Shenzhen district compared with other typhoons.
Although Ewiniar was not the strongest typhoon in 2018 , it induced the heaviest precipitation on Shenzhen since 2013.

Historical data of meteorological variation in Shenzhen from years of 2008 to 2018 [1] are summarized in Fig. 5. As shown in Fig. 5 (a), the number of typhoons which entered $500 \mathrm{~km}$ range circle of Shenzhen and induced obvious rainfall show no clear relationship with temperature anomaly, while typhoons with severe impact show an obvious increase since 2009. Similarly, the relationship between the duration of both regional and citywide rainfalls with DPs larger than $50 \mathrm{~mm}$ and temperature anomaly is not clear, as shown in Fig. 5 (b), which may be induced by the combined effects of urbanization, climate warming and extreme weather of typhoon. Further, the citywide rainfalls with DPs larger than $100 \mathrm{~mm}$ show an increasing tendency since 2011. The number of typhoons with severe impact and the duration of citywide rainfalls with DPs larger than 100 $\mathrm{mm}$ together prove the fact that typhoons induced by climate warming show an increasing destructive potential and often accompanied by extreme intense rainfall. The indicator of comprehensive annual index of typhoon impact (CAITI), reflecting the combined impacts of rainfall, wind and others induced by all typhoons in a year, is adopted to evaluate severity degree of the loss related to typhoon on Shenzhen. As shown in Fig. 5 (c), the CAITIs show an overall increasing tendency since 2013, which is consistent with the variation of the duration of citywide rainfalls with DPs larger than $100 \mathrm{~mm}$. Specially, the CAITI of 2018 reached 76.8 which indicated the severest impact induced by typhoons on Shenzhen since 2008.

\section{Influence of intense rainfall on operation safety and service life of asphalt pavement Characteristics of water film thickness for asphalt pavement}

In intense rainfall weather, the residual convergent runoff on the surface of asphalt pavement adversely affects driving safety and intensifies with water film thickness. It is of great significance to investigate characteristics of water film thickness and surface runoff on asphalt pavement in intense rainfall weather, which is not only

Table 1 Criteria and classification of urban waterlogging for typical regions [33]

\begin{tabular}{|c|c|c|c|c|c|c|}
\hline \multirow[b]{2}{*}{ Regions } & \multicolumn{3}{|l|}{ Criteria } & \multicolumn{3}{|l|}{ Classification } \\
\hline & Depth $\mathrm{H} / \mathrm{cm}$ & Scope S/ m² & Period $t / \min$ & Mild & Medium & Severe \\
\hline Normal straight road & $\geq 15$ & $\geq 300$ & $\geq 60$ & $15 \leq H<25$ & $25 \leq H<40$ & $H \geq 40$ \\
\hline Crossroads & $\geq 15$ & $\geq 100$ & $\geq 30$ & $15 \leq H<25$ & $25 \leq H<40$ & $H \geq 40$ \\
\hline Concave bridge & $\geq 27$ & $\geq 100$ & $\geq 30$ & $27 \leq H<35$ & $35 \leq H<45$ & $H \geq 45$ \\
\hline Subway entrance & $\geq 25$ & $\geq 50$ & $\geq 15$ & $25 \leq H<35$ & $35 \leq H<65$ & $H \geq 65$ \\
\hline Underground garage entrance & $\geq 15$ & $\geq 100$ & $\geq 30$ & $15 \leq H<25$ & $25 \leq H<30$ & $H \geq 30$ \\
\hline
\end{tabular}


$\square$ Entering $500 \mathrm{~km}$ range circle $\square$ Inducing obvious rainfall $\square$ Severe impact

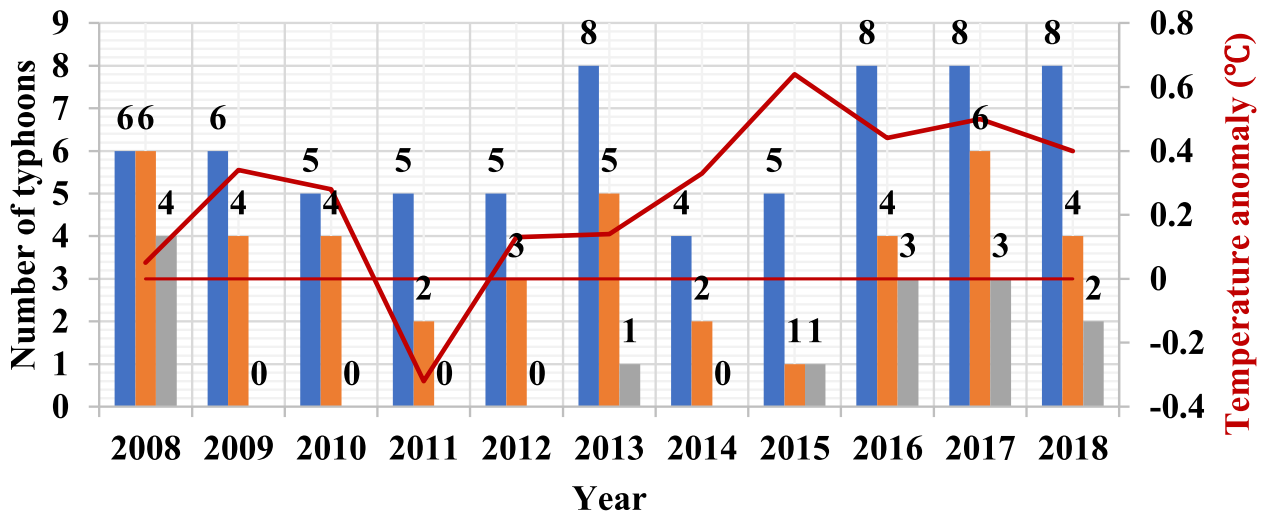

(a) Number of typhoons impacting Shenzhen

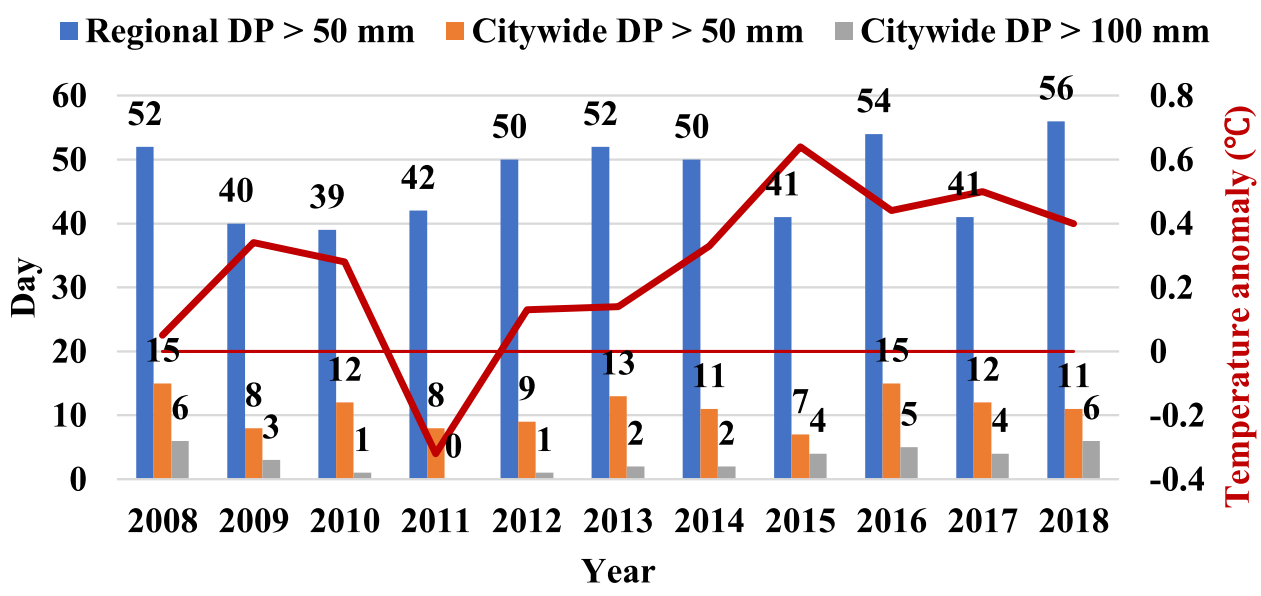

(b) Rainfall days

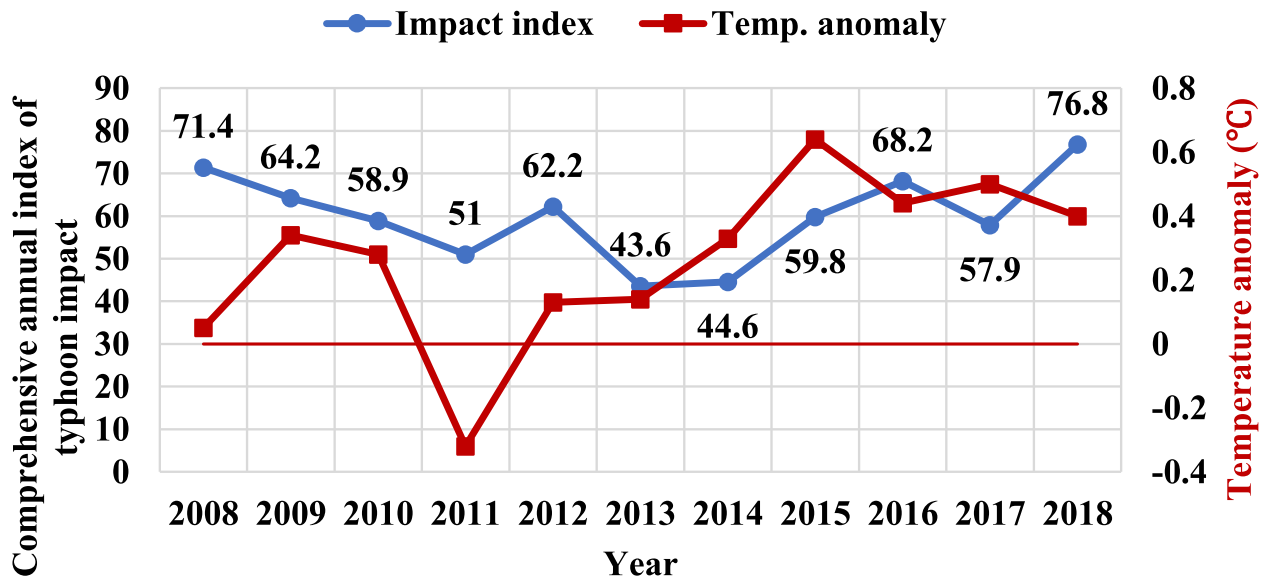

(c) Variation of comprehensive annual index of typhoon impact

Fig. 5 Meteorological variation in shenzhen from years of 2008 to 2018 [1] 
beneficial to ensure the normal and safe operation of asphalt pavement, but also lays research foundations to optimize drainage forms of asphalt pavement structure design.

There are mainly two types of prediction models of water film thickness for asphalt pavement, which are mathematical physics model and regression model. The mathematical physics model such as the Saint-Venant equation considers water film as a shallow water wave with stable water flow and can describe its basic motion characteristics. However, the analytical solution of slope flow is often obtained from the simplified mathematical physics model according to the actual conditions of the road's surface runoff [36]. The regression model uses a large amount of experimental data to calibrate model parameters among variables of hydrological phenomena and obtains mathematical functions via regression methods. The main factors affected the depth of water film $d$ mainly include drainage length $L$, rainfall intensity $I$, slope gradient $S$, and average texture depth $T D$. Efforts had been made to observe water film thickness and relevant empirical models were obtained, as shown in Table 2.

The Road Research Laboratory (RRL) model (1) and the Anderson model (4) are in the same form with only difference in coefficient values. The Gallaway model (2) and the Wambold model (3) are also similar in form, but the latter was only suitable for the case with drainage length of $11 \mathrm{~m}$. Ji et al. [41] measured water film thickness and regressed an empirical model based on 195 tests, which were conducted on three field test roads constructed by three different types of asphalt mixture and three slope gradients, respectively. Compared with the Anderson model (4), the regression model (5) took the texture depth TD into account and could predict the measured field data with a correlation coefficient of 0.96 . Luo et al. [42] also conducted water film thickness observation experiments using full-scale prefabricated asphalt pavement specimens, which had a dimension of 6 $\mathrm{m} \times 3 \mathrm{~m}$ and took three types of asphalt mixture and geometric parameters into account. It was found that both the RRL model (1) and the Gallaway model (2) had the least difference from the proposed regression model (6), while the prediction accuracies of regression models

Table 2 Prediction models for water film thickness

\begin{tabular}{lll}
\hline Authors & Models & No. \\
\hline Ross and Russam [37] & $d=0.017 \times\left(L \cdot l^{0.47} S^{-0.2}\right.$ & (1) \\
Gallaway [38] & $d=3.38 \times 10^{-3} \times\left(T D^{0.11} L^{0.43} \rho .59 S^{-0.42}\right)-T D$ & (2) \\
Wambold [39] & $d=5.979 \times 10^{-3} \times T D^{0.11} \rho .59 S^{-0.42}-T D$ \\
John Anderson [40] & $d=0.15 \times\left(L \cdot l^{0.5} S^{-0.5}\right.$ & \\
Ji et al. [41] & $d=0.1258 \times L^{0.6715} S^{-0.3147} \rho^{0.7786} T D^{0.7261}$ \\
Luo et al. [42] & $d=0.068 \times L^{0.32} S^{-0.31} \rho^{0.41} T D^{1.17}$
\end{tabular}

were higher than Manning formula. Since the observed water film thicknesses used in calibration of regression models were easily affected by experimental conditions, differences unavoidably existed in parameters of each regression model. Luo et al. [42] emphasized that the water film which affected the variation of friction coefficient of road surface layer should be characterized by average water film thickness, which took surface macrostructure thickness into account. The method of artificial neural network suggests constructing prediction model of water film thickness [43], for the purpose of making full use of previous research data and conducting as few trials as possible.

\section{Risk of driving safety in intense rainfall weather}

There are four interaction states between vehicle tires and pavement surface layer when a vehicle drives on the asphalt pavement with surface runoff. There is no contact between tires and pavement surface layer existing in front of tire regions due to the backwater phenomenon [44]. In the incomplete contact region between tires and pavement surface layer, free water flow has been squeezed out, while the water flow inside space between tire tread patterns and macro structure of surface pavement layer will be canalized and also drained as much as possible. The confined cavity formed by complete contact between tires tread patterns and pavement surface layer will be further compressed, which drives water flow to hydraulically scour asphalt binder film on the inner wall of connected void channels. Finally, a certain vacuum degree formed behind tires will pump water flow out of connected void channels. Lei et al. [45] measured the dynamic pore water pressure generated inside asphalt pavement using a designed sensor device, and a maximum positive pressure of $0.115 \mathrm{MPa}$ and a maximum negative pressure of $-0.073 \mathrm{MPa}$ were obtained under a vehicle speed of $100 \mathrm{~km} / \mathrm{h}$. The tread patterns of vehicle tires are often designed to combine patterns with different directions according to the characteristics of diverse driving environment, as shown in Fig. 6.

When the thickness of surface runoff on asphalt pavement is small, water can be drained in time by tread grooves to ensure enough friction between vehicle tires and pavement surface layer. However, when the thickness of surface runoff induced by intense rainfall is too large to be drained in time, vehicle tires will be lifted by water flow and not contact tightly with pavement surface layer, the resulting aquaplaning phenomenon will seriously do harm to operation safety of urban roads. Dong et al. [47] established a road-tire finite element model under the condition of pavement surface runoff based on computational fluid dynamics theory to investigate aquaplaning phenomenon of vehicle tires. It was found that the lifting force of tires increased obviously with 

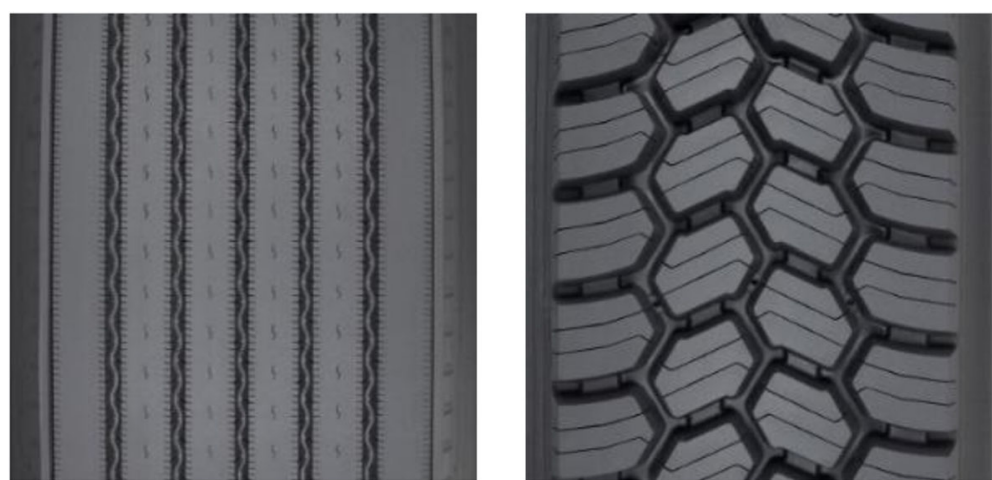

Fig. 6 Different tire tread patterns [46]

vehicle speed larger than $60 \mathrm{~km} / \mathrm{h}$, as shown as Fig. 7 . Dynamic pore water pressure increased slowly with vehicle speed when water film thickness was less than tire tread depth, but water pressure increased parabolically once water flow exceeded the drainage capacity of tire tread patterns. The critical aquaplaning state is emerged when the external generated dynamic pore water pressure gradually increases and equals to the tire's inner pressure. Li et al. [48] numerically simulated the aquaplaning phenomenon for a tire with the tread depth of 7 $\mathrm{mm}$. It was found that the critical driving speeds for water film thicknesses of $8 \mathrm{~mm}$ and $12 \mathrm{~mm}$ were 120 $\mathrm{km} / \mathrm{h}$ and $100 \mathrm{~km} / \mathrm{h}$, respectively.

Liu et al. [49] built an asphalt pavement model with macro texture features and a tire model with tread pattern to numerically calculate the contact force variation curve and the critical hydroplaning speed. It was found that the increase of the complexity of tire tread patterns could decrease the lift force of water flow to tires, while the increase of the tire inflation pressure and the decrease of water film thickness could increase the contact force and the critical hydroplaning speed. The open graded friction course (OGFC) pavement with high mean profile depth (MPD) was found to have relatively good ability to prevent hydroplaning than asphalt

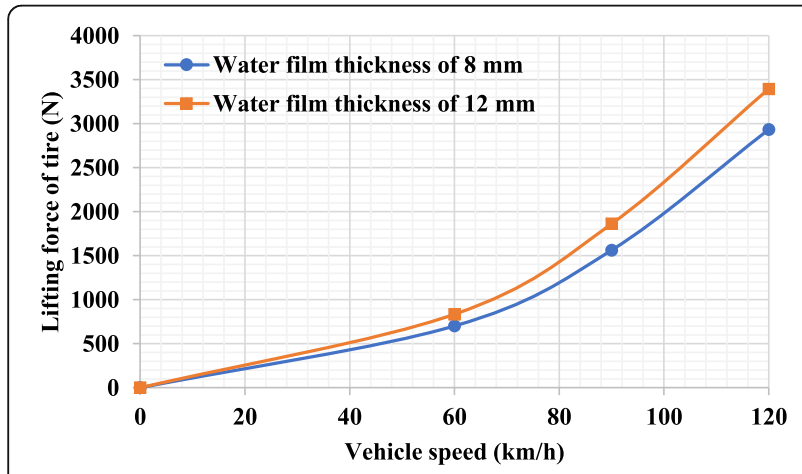

Fig. 7 Relation between lifting force and vehicle speed [47] concrete (AC) and stone matrix asphalt (SMA) pavement. Therefore, measures should be taken to ensure enough drainage capacity of canalized channels composed of tire tread patterns and surface macro structure to relieve the aquaplaning phenomenon, such as timely replacement of worn tires [50] or preventive maintenance of enough macro-structure recovery on pavement surface.

The water mist splashed by vehicle tires is also a nonnegligible factor, as shown in Fig. 8, which reduces the visibility of rear vehicles and seriously affects driving safety. The decreased vehicle speed and increased driving safety interval also reduce the operational efficiency of urban traffic. Billot et al. [51] investigated the influence of three different rain intensities on traffic capacity and the decreases from $18.5 \%$ to $21 \%$ were obtained respectively. Agarwal et al. [52] analyzed the relationship between rainfall intensity and traffic flow based on measured field data. It was found that traffic flow would decrease $1 \%$ to $3 \%$ when rainfall intensity was smaller than $0.25 \mathrm{~mm} / \mathrm{h}$, while the decrease extent would be $5 \%$ to $10 \%$ as rainfall intensity was $0.25 \mathrm{~mm} / \mathrm{h}$ to $6.35 \mathrm{~mm} / \mathrm{h}$. Compared with dry weather, Zhang et al. [53] found that

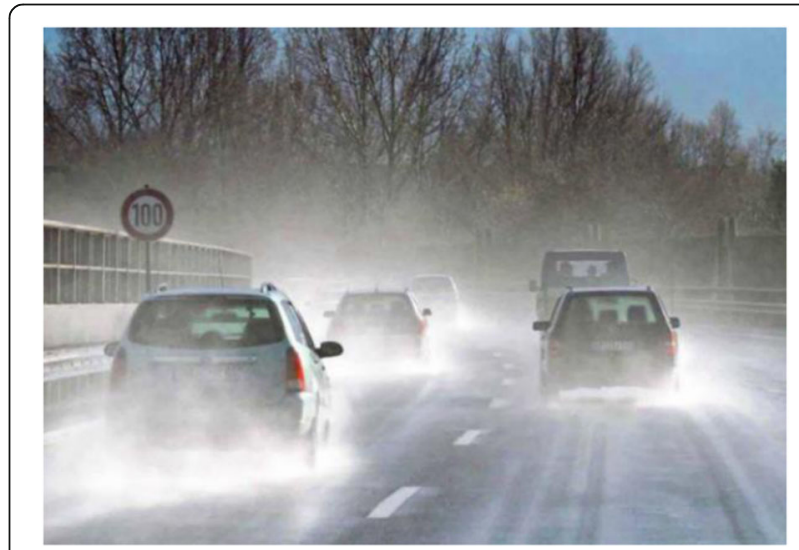

Fig. 8 Water mist splashed by vehicle tires 
the average driving speed in the urban freeway system would decrease $4.7 \%, 9.8 \%$ and $16.1 \%$ in light, medium and heavy rain weather, respectively. The environment light in rainy weather is weak and thus results in dark vision, which makes it hard for drivers to quickly make a correct judgment on actual conditions of road traffic $[54,55]$. In case of emergency circumstances, the severe brake action of vehicles with a relative high driving speed may cause dangerous accidents such as rear-end collision or side-slip. Black et al. [56] analyzed statistic data of rainfall and vehicle crashes from years of 1996 to 2010 for six U.S. states, while an overall increase in crashes of $51 \%$ was concluded during days with more than $50 \mathrm{~mm}$ of rainfall.

\section{Influence of intense rainfall on service life of asphalt pavement}

The increasing frequent occurrence of intense rainfall induced by climate warming increases the interaction between water and asphalt pavement. The increased water film thickness induced by the intensified rainfall results in larger dynamic pore water pressure generated inside asphalt pavement under vehicle loads. The dynamic water flow, which is formed by the repeated alternative processes of squeezing and pumping action driven by tires, continuously scours surface layer of asphalt pavement. Figure 9 shows a schematic diagram of dynamic hydraulic scouring induced by repeated loading of vehicle tires on asphalt pavement with surface runoff. This dynamic hydraulic scouring will gradually split asphalt binder film and finally develop into moisture damage in forms of raveling or potholes [8], which makes entire service properties and service life of asphalt pavement subject to be challenged.

Moisture damage of asphalt materials induced by dynamic pore water pressure exhibits a totally different damage mechanism compared with that induced by static water immersion and freeze-thaw $[9,57,58]$. A series of water conditioning devices were developed [5962] to simulate the environment of dynamic pore water

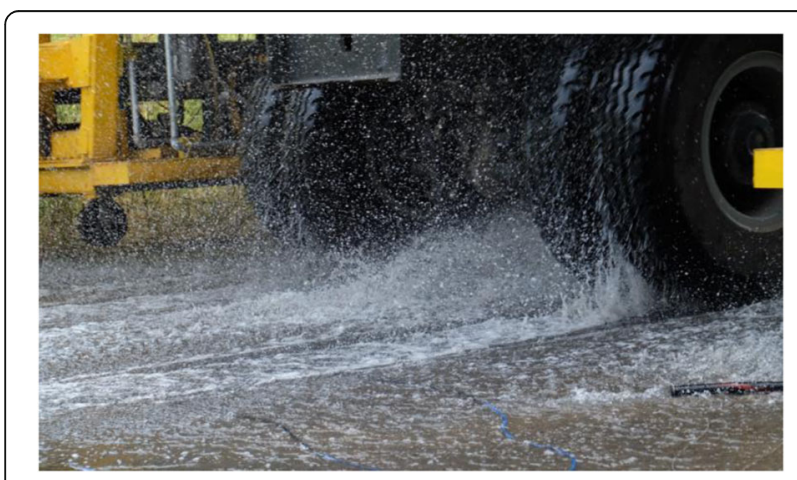

Fig. 9 Hydraulic scouring induced by a moving vehicle pressure and evaluate the service life of asphalt materials. Multi-scale experiments were correspondingly conducted to investigate moisture damage issues [59, 63, 64]. Service properties of asphalt mixture such as mechanical strength, high temperature stability, low temperature cracking resistance and fatigue resistance were affected by environmental parameters of dynamic pore water pressure, which included magnitude, frequency, water temperature and duration [65]. At present, there is no standard microscopic experimental methods based on dynamic pore water pressure conditioning for moisture damage evaluation of asphalt mixture yet. It is still necessary to develop conditioning experimental devices which can really simulate actual service environment that combined factors of dynamic mechanical loading, pore water pressure and temperature together for service life evaluation of asphalt pavement.

Pervious pavement has a high permeability due to its characteristic connected void channels. As an important part of sponge city construction, the runoff features of pervious pavement play an important role on management of intense rainfall for urban transportation infrastructure. Zhang et al. [66] simulated the interaction process between intense rainfall runoff and pervious pavement. It was found that average flow velocity and shear velocity in surface runoff regions increased with permeability of pervious pavement. The inflow rate of surface layer also increased with rainfall intensity which shortened time consumption for lower layers of pavement structure to reach saturation state [67]. Under the combined effects of vehicle load, water and temperature, dynamic response on asphalt pavement structure would make properties of seepage, fatigue and cracking be challenged, which increased the possibility of asphalt binder film being stripped and reduced overall service life of asphalt pavement [68].

Water of urban waterlogging disasters induced by intense rainfall is often mixed with silt. The dirty water spreads everywhere causing pollution on asphalt pavement surface layer, which will decrease the permeability of pervious pavement as its pore structure is clogged. Cui et al. [69] simulated intense rainfall process by spraying sodium chloride $(\mathrm{NaCl})$ solution on permeable concrete specimens, and evenly sprinkled sand onto specimens' top side to simulate blockage process caused by intense rainfall mixed with silt. It was found that the pore clogging process of pervious pavement consisted of three stages, namely quick clogging, temporary of clogging and progressive clogging. The conductivity change of pervious specimen could accurately reflect the clogging degree of its pore structure. Zhou et al. [70] conducted a dust clogging test to investigate the decay law of permeability performance for porous asphalt pavement. It 
was found that the residual rate of permeability coefficient was linearly related to dust particle's quality, while the decay rate of permeability coefficient was proportional to the initial porosity.

After urban waterlogging, it is essential to clean blocked regions on asphalt pavement surface layer in time to recover its water-permeable function. As shown in Fig. 10, there are mainly two kinds of urban road cleaning methods which are high-pressure water spraying type and sweeping suction type. As water immersion gradually weaken bond strength inside asphalt materials, road cleaning may bury a potential risk of particles shedding which put forward a high requirement on scouring resistance of asphalt materials in pavement surface layer.

\section{Mitigation measures}

To deal with impacts of a series of climatic disasters on human life, Paris Climate Agreement was adopted in December 2015 [71] and many countries are taking steps to control carbon emissions based on their own national situations. Measures to deal with global warming mainly include two categories of carbon dioxide removal and solar radiation management [72]. The former mainly tries to remove carbon dioxide content in atmosphere by the artificial means, which includes carbon dioxide capture and storage, biomass carbon capture, land use management and so on [73]. The latter mainly directly cools earth surface by influencing solar radiation, which mainly includes stratospheric aerosol injection, setting space mirrors, desert greening, white roofing and whitening of ocean clouds to change the surface albedo [74]. In order to investigate China's control of carbon dioxide emissions in its rapid urban industrialization, Shan et al. [75] compiled lists of carbon dioxide emissions on cityscale and then analyzed characteristics of carbon dioxide emissions. It was pointed out that different emission reduction strategies of low-carbon development paths should be proposed respectively according to different industrialization stages of cities in China.

To deal with urban waterlogging disasters, the State Council of the Chinese Government officially promulgated a notification in March 2013 [76] to make clear requirements and deployment on urban waterlogging prevention and control on the national level. Maintaining and restoring vegetation cover is a key consideration in mitigating the urban heat island [30], which can reduce the impact of urbanization on intense rainfall formation. The concept of the sponge city [77], which is consisted of pervious pavement, roof greening, infiltration ditch, storage tank and so on, has a good ability to adjust and control water flow of intense rainfall. It is a complex and systematic project to solve the problem of urban waterlogging [78], which not only requires a reasonable city construction planning and an upgrading of drainage network system, but also needs sufficient attention to be paid on some important aspects as shown below:

- Carry out reasonable modeling and analysis of urban waterlogging forecast to provide the basis for government decision-making.

- Improve the accuracy of weather forecasting for early warning of urban waterlogging.

- Build up supporting policies and regulations for urban waterlogging prevention.

To mitigate the impact of intense rainfall with frequent occurrence on urban asphalt roads, the most important and direct measure is to deal with atmospheric precipitation timely and minimize the influence of stagnant water on traffic operation and road service conditions. Road drainage facilities should be well designed and constructed for urban pavement or highway to digest atmospheric precipitation as fast as possible and avoid forming stagnant layer on pavement surface [48]. It is feasible to ensure safe and effective operation of urban transportation in intense rainfall weather by controlling traffic flow parameters such as driving speed and safety interval. The increasing frequent occurrence of intense rainfall increases the possibility of moisture damage on asphalt pavement and results in service performance degradation induced by dynamic pore water pressure with positive and negative alternation, which is quite different

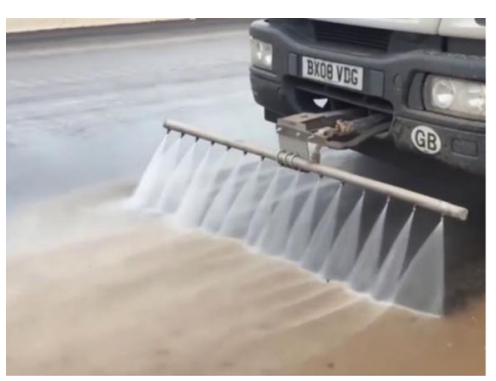

(a) Spraying

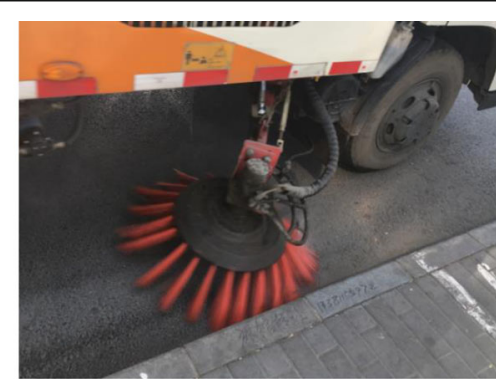

(b) Sweeping

Fig. 10 Two ways to clean asphalt pavement 
from moisture damage processes induced by freezing expansion or static water immersion. Therefore, it is necessary to make further research on moisture damage mechanisms of asphalt pavement induced by dynamic pore water pressure and propose the design system of asphalt pavement with high service performance and long service life under the background of climate warming.

\section{Conclusions}

The study reviewed the characteristics of intense rainfall induced by climate warming and its influence on urban asphalt pavement. The following conclusions can be drawn as below:

1) Global climate warming accompanied by the accelerating water evaporation of land and sea surface in recent years promotes the formation of typhoons. The power dissipation index (PDI) of tropical cyclone indicates an upward trend in destructive potential and is followed by an increasing occurrence frequency of extreme rainfall weather. The intense rainfall with the daily precipitation (DP) index larger than $50 \mathrm{~mm}$ is highly related to climate warming and multiple island effects of urbanization such as heat, turbidity and water vapor. The intense rainfall weather in flood season often has the features of high rainfall intensity, high frequent occurrence and short duration.

2) The urban waterlogging induced by extreme intense rainfall often has a wide-ranged severe impact on urban transportation. Both the reducing rainwater storage capacity and the hysteretic urban construction of rainwater pipe network are non-negligible factors causing urban waterlogging. Specially, the severity of intense rainfall is highly related with the distance between urban regions and the typhoon center according to the analysis of Shenzhen case. The indicator of comprehensive annual index of typhoon impact (CAITI) can well evaluate the impact degree of extreme rainfall weather and urban waterlogging induced on urban regions.

3) General intense rainfall weather increases water film thickness on asphalt pavement surface layer and reduces frictional resistance between vehicle tires and pavement surface layer. The prediction models of water film thickness which take more factors of asphalt roads' features into account often have relatively good accuracies. The resulting aquaplaning phenomenon not only has adverse impacts on driving, but also decreases operation efficiency of urban transportation and causes safety risks.
4) The dynamic response of saturated asphalt pavement and the generated dynamic pore water pressure aggravates moisture damage to asphalt materials. The dirt water of urban waterlogging pollutes asphalt pavement surface layer, which will decrease road's permeability as its pore structure is clogged. Specially, urban road cleaning also raises a potential risk on bonding failure of asphalt materials' particles.

5) Measures are proposed in aspects of carbon emissions control, sponge city, and improvement of road drainage facilities to mitigate the influence of intense rainfall induced by climate warming. It is feasible to control traffic flow parameters to ensure driving safety and traffic operation efficiency. Further efforts need to be made in the future to improve design system of asphalt pavement considering the factor of dynamic porewater pressure.

\section{Abbreviations}

AC: Asphalt concrete; CAITI: Comprehensive annual index of typhoon impact; CAPE: Convective available potential energy; DP: Daily precipitation;

PDI: Power dissipation index; MPD: Mean profile depth; OGFC: Open graded friction course; RRL: Road research laboratory; SMA: Stone matrix asphalt

\section{Acknowledgements}

Not applicable.

\section{Authors' contributions}

Conceptualization, W.W. and L.W.; Methodology, W.W., Y.M. and L.W.; Validation, W.W. and L.W.; Investigation, W.W., C.C. and S.C.; Data curation, W.W., C.C. and S.C.; Writing-Original Draft Preparation, W.W.; Writing-Review and Editing, W.W., Y.M. and L.W.; Visualization, W.W.; Supervision, L.W. The authors read and approved the final manuscript.

\section{Funding}

Not applicable.

Availability of data and materials

The datasets used and/or analysed during the current study are available from the corresponding author on reasonable request.

\section{Competing interests}

The authors declare that they have no competing interests.

\section{Author details}

${ }^{1}$ National Center for Materials Service Safety, University of Science and Technology Beijing, No.30, Xueyuan Road, Haidian District, Beijing 100083, China. ${ }^{2}$ Joint USTB-Virginia Tech Lab on Multifunctional Materials, USTB, Beijing 100083, China. ${ }^{3}$ Virginia Tech, Blacksburg, VA 24061, USA.

Received: 23 October 2019 Accepted: 13 February 2020

Published online: 23 March 2020

References

1. Meteorological Bureau of Shenzhen Municipality. (2019). "Shenzhen climate bulletin 2018." http://weather.sz.gov.cn/qixiangfuwu/qihoufuwu/ qihouguanceyupinggu/nianduqihougongbao/201901/t20190116_15306885. htm. (Last accessed 9 Feb 2020)

2. Hu H (2015) Spatiotemporal characteristics of rainstorm-induced hazards modified by urbanization in Beijing. J Appl Meteor Climatol 54:1496-1509

3. Gao F, Liu P, Huang C (2017) Analysis and responses of the waterlogging in Wuhan city based on system thinking. J. Catastrophology 32(3):101-106 
4. Debbage N, Shepherd J (2019) Urban influences on the spatiotemporal characteristics of runoff and precipitation during 2009 Atlanta flood. J Hydrometeorol 20:3-21

5. Schroeder A, Basara J, Shepherd J, Nelson S (2016) Insights into atmospheric contributors to urban flash flooding across the United States using an analysis of rawinsonde data and associated calculated parameters. J. Appl. Meteor. Climatol. 55:313-323

6. Xie Y (2013) Development of drainage planning in view of frequent urban waterlogging disasters. City Planning Rev 2:45-50

7. Xue Q, Liu L (2013) Hydraulic-stress coupling effects on dynamic behavior of asphalt pavement structure material. Constr Build Mater 43(3):31-36

8. Wang W, Wang L, Xiong H, Luo R (2019) A review and perspective for research on moisture damage in asphalt pavement induced by dynamic pore water pressure. Constr Build Mater 204:631-642

9. Varveri A, Zhu J, Kringos N (2015) "Moisture damage in asphaltic mixtures, advances in asphalt materials: road and pavement construction." Woodhead Publishing, Kidlington. ISBN: 978-0-08-100269-8, 303-344.

10. Blunden J, Arndt D (2019) State of the climate in 2018. Bull Amer Meteor Soc 100(9):48-60

11. National Centers for Environmental Information. (2019). "Climate at a Glance. " https://www.ncdc.noaa.gov/cag/global/time-series/globe/land_ocean/ytd/ 12/1880-2018. (Last accessed 9 Feb 2020)

12. Trenberth K, Fasullo J, Smith L (2005) Trends and variability in columnintegrated atmospheric water vapor. Climate Dyn 24:741-758

13. Trenberth K (2005) Uncertainty in hurricanes and global warming. Science 308:1753-1754

14. Emanuel K (2005) Increasing destructiveness of tropical cyclones over the past 30 years. Nature 436:686-688

15. Kanada S, Takemi T, Kato M et al (2017) A multimodel intercomparison of an intense typhoon in future, warmer climates by four $5-\mathrm{km}$-mesh models. $J$ Clim 30:6017-6036

16. Yamada Y, Satoh M, Sugi M et al (2017) Response of tropical cyclone activity and structure to global warming in a high-resolution global nonhydrostatic model. J Clim 30:9703-9724

17. Administration CM (2016) QX/T 341-2016 the intensity grade of rainfall process. China Meteorological Press, Beijing

18. Yang L, Smith J, Wright D et al (2013) Urbanization and climate change: an examination of nonstationarities in urban flooding. J Hydrometeorol 14: 1791-1809

19. Chen $Y$, Yu B, Jenkins $G$ (2013) Secular variation in rainfall intensity and temperature in eastern Australia. J Hydrometeorol 14:1356-1363

20. Trenberth K, Dai A, Rasmussen R, Parsons D (2003) The changing character of precipitation. Bull Amer Meteor Soc 84(9):1205-1217

21. Chen S (2019) Multi-year variation of precipitation and rain island effect in Shenzhen. Adv Meteor Sci Technol 9(3):166-170

22. Miao S, Chen F, Li Q, Fan S (2011) Impacts of urban processes and urbanization on summer precipitation: a case study of heavy rainfall in Beijing on 1 august 2006. J Appl Meteor Climatol 50:806-825

23. Nie W, Zaitchik B, Ni G, Sun T (2017) Impacts of anthropogenic heat on summertime rainfall in Beijing. J Hydrometeorol 18:693-712

24. Dou J, Wang Y, Bornstein R, Miao S (2015) Observed spatial characteristics of Beijing urban climate impacts on summer thunderstorms. J Appl Meteor Climatol 54:94-105

25. Fang G, Gao Y, Xu L et al (2012) Analysis of precipitation change and the characteristics of disaster rainfalls in Shanghai. Resour Environ Yangtzs Basin 21(10):1270-1273

26. Frich P, Alexander L, Della-Marta P et al (2002) Observed coherent changes on climatic extremes during the second half of the twentieth century. Clim Res 19(3):193-212

27. Yang P, Ren G, Yan P (2017) Evidence for a strong association of shortduration intense rainfall with urbanization in the Beijing urban area. J Clim 30:5851-5870

28. Gu W, Wang L, Hu Z et al (2018) Interannual variations of the first rainy season precipitation over South China. J Clim 31:623-640

29. Zhang L, Yu L, Ren X, Sun X (2015) Construction strategy of sponge city based on historical waterlogging survey in Shenzhen. China Water Wastewater 31(23):120-124

30. Chapman S, Thatcher M, Salazar A et al (2018) The effect of urban density and vegetation cover on the heat island of a subtropical city. J Appl Meteor Climatol 57:2531-2550
31. Liu Z, Zhou Y, Liu S et al (2015) Approach of building content damage assessment and risk quantification by urban local flooding based on GIS. J Beijing Univ Technol 41(2):275-280

32. Sun Z (2014) Causal factors of local floods in Beijing central city. Geo Res 33(9):1668-1679

33. Zhang S, Xiao Z, Wang Z, Pan X (2019) Quantitative study on the criteria for determining urban flood in Beijing. China Flood Drought Management 29(9): $1-5$

34. Li M, Kwan M, Wang F, Wang J (2018) Using points-of-interest data to estimate commuting patterns in Central Shanghai, China. J Transp Geo 72: $201-210$

35. Li R, Zhou W (2015) Interdecadal changes in summertime tropical cyclone precipitation over Southeast China during 1960-2009. J Clim 28:1494-1509

36. Ji T (2004) Influence of rainfall on tire and pavement friction coefficient. In: Doctor of science, thesis, Southeast University

37. Ross N, Russam K (1968) The depth of rain water on road surfaces. Road Research Laboratory, Ministry of Transport, Crowthorne

38. Gallaway B, Schiller R, Rose J (1971) The effects of rainfall intensity, pavement cross slope, surface texture, and drainage length on pavement water depths. Texas Transportation Institute, College Station

39. Wambold J, Henry J, Hegmon R (1982) Evaluation of pavement surface texture significance and measure techniques. Wear 83(2):351-368

40. Anderson J (1995) Depth of rain water on road surface. Highw Transp 42(5): 45-49

41. Ji T, Huang X, Liu Q, Tang G (2004) Test depth of water film on asphalt pavement surface. J Highw Transp Res Dev 21(12):14-17

42. Luo J, Liu J, Wang Y (2015) Validation test on pavement water film depth prediction model. China J Highw Transp 28(12):57-63

43. Ji T, Huang X, Liu Q, Tang G (2004) Prediction model of rain water depth on road surface. J Traffic Transp Eng 4(3):1-3

44. Wang B (2015) Influence of rainfall on traffic safety of highway. China Water Transp 15(7):229-230

45. Lei $Y$, Hu X, Wang $\mathrm{H}$ et al (2017) Effects of vehicle speeds on the hydrodynamic pressure of pavement surface: measurement with a designed device. Measurement 98:1-9

46. Michelin America. (2017). "MICHELIN truck tire data book." https://www. michelinb2b.com/wps/b2bcontent/PDF/MICHELIN_Truck_Tires_Reference_ Chart 4x9.pdf. (Last accessed 9 Feb 2020)

47. Dong Q, Li Y, Shi X et al (2013) Calculation and analysis of hydrodynamic pressure on road surface. J Chang'an Univ (Nat Sci) 22(5):17-22

48. Li Z, Wang J, Li Y, Zhao Y (2011) The general technique to protect and drain water on road. China Communication Press, Beijing. ISBN: 978-7-11406292-6, pp 3-6

49. Liu X, Cao Q, Zhu S et al (2017) Numerical simulation of tire critical hydroplaning speed on asphalt pavement. J Southeast Univ (Nat Sci) 47(5): 1020-1025

50. Hu X, Sun L, Walubita LF (2009) Laboratory measurement of the actual tirepavement contact pressure using a static test device. J Test Eval 38(1):19-31

51. Billot R, Faouzi N, Vuyst F (2009) Multilevel assessment of the impact of rain on drivers' behavior: Standardized methodology and empirical analysis. Transp Res Rec 2107:134-142

52. Agarwal M, Maze T, Souleyrette R (2006) "The Weather and its impact on urban freeway traffic operations." Presented at $85^{\text {th }}$ Annual Meeting of the Transportation Research Board, Washington, D. C., 06-1439

53. Zhang C, Wan P, Mei Z, Zhang P (2013) Traffic flow characteristics and models of freeway under rain weather. J Wuhan Univ Technol 35(3):63-67

54. Abdel-Aty M, Hassan H, Ahmed M, Al-Ghamdi A (2012) Real-time prediction of visibility related crashes. Transp Res Part C 24:288-298

55. Yuan J, Abdel-Aty M, Wang L, et al (2018) "Real-time crash risk analysis of urban arterials incorporating bluetooth, weather, and adaptive signal control data." Presented at 97th Annual Meeting of the Transportation Research Board, Washington, D. C., 18-00590

56. Black A, Villarini (2016) Effects of rainfall on vehicle crashes in six U.S. states. Wea Climate Soc 9:53-70

57. Mehrara A, Khodaii A (2013) A review of state of the art on stripping phenomenon in asphalt concrete. Constr Build Mater 38:423-442

58. Kakar MR, Hamzah MO, Valentin J (2015) A review on moisture damages of hot and warm mix asphalt and related investigations. J Clean Prod 99:39-58

59. Jiang W, Zhang X, Li Z (2011) Mechanical mechanism of moisture induced damage of asphalt mixture based on simulation test of dynamic water pressure. China J Highw Transp 24(4):21-25 
60. Hou M, Tan Y, Hu B (2012) Dynamic water effect on the high temperature stability of asphalt mixture. Adv Eng Forum 5:352-357

61. Guo Y, Shen A (2018) The preventive maintenance of fiber reinforced chip seal. China Communication Press Co., Ltd, Beijing ISBN: 978-7-114-13725-9, pp 269-272

62. Pan B, Shao L, Wang Z (2009) New method for studying water impairment of asphalt pavement. J Wuhan Univ Technol (Transp Sci Eng) 33(2):250-252

63. Lacroix A, Regimand A, James $L$ (2016) Proposed approach for evaluation of cohesive and adhesive properties of asphalt mixtures for determination of moisture sensitivity. Transp Res Rec 2575:61-69

64. Tan Y, Hou M, Zhang L et al (2014) Studying the strain field distribution of asphalt mixture with digital speckle correlation method. Road Mater Pavement Des 15(1):90-101

65. Hu B (2007) Influence of water on the road performance of asphalt mixture. In: Master of science, thesis, Harbin Institute of Technology

66. Zhang J, Cui X, Tang W, Lou J (2017) Approximate simulation of storm water runoff over pervious pavement. Int J Pavement Eng 18(3):247-259

67. Liu M (2007) Numerical simulation and analysis of unsaturated seepage flow characteristics of pavement structure. In: Master of science, thesis, Hunan University

68. Yang R (2011) Study on fatigue failure of asphalt concrete under unsaturated coupled seepage-stress field. In: Master of science, thesis, Chongqing Jiaotong University

69. Cui X, Zhang J, Huang D et al (2016) Experimental simulation of rapid clogging of pervious concrete pavement under effects of rainstorm. China J Highw Transp 29(10):1-12

70. Zhou W, Huang X, Liang Y, Shang B (2016) Permeability performance decay law of porous asphalt pavement. J Chang'an Univ (Nat Sci) 36(1):21-27

71. United Nations. (2015). "Paris agreement". http://unfccc.int/files/essential_ background/convention/application/pdf/english_paris_agreement.pdf. (Last accessed 9 Feb 2020)

72. Kong F, Sun S, Shi W et al (2018) Study on the impact of climate engineering on extreme rainfall intensity in China from 2010 to 2099. J Catastrophology 33(2):106-113

73. Zhang Y, Chen Y, Pan J (2016) Key issues in climate engineering economic assessment and governance. Adv Climate Change Res 12(5):442-449

74. Pan J (2012) Key issues related to Geo-engineering as approaches to climate change mitigation. China Population Resour Environ 22(5):22-26

75. Shan Y, Guan D, Hubacek K et al (2018) City-level climate change mitigation in China. Sci Adv 4:eaaq0390

76. General Office of the State Council of the People's Republic of China. (2013), "Notice on the construction of urban drainage and waterlogging prevention facilities". http://www.gov.cn/zhengce/content/2013-04/01/ content_5066.htm. (Last accessed 9 Fe 2020)

77. Wang J, Zhang Q, Wu L, Gou A (2013) Review on research about urban waterlogging in China. J Anhui Agric Sci 41(30):12072-12078

78. Li H, Zhao W, Zhang C et al (2019) Technology and application of permeable pavement for sponge city. Tongji University Press, Shanghai. ISBN: 978-7-5608-8361-8, pp 1-12

\section{Publisher's Note}

Springer Nature remains neutral with regard to jurisdictional claims in published maps and institutional affiliations.

\section{Submit your manuscript to a SpringerOpen ${ }^{\circ}$ journal and benefit from:}

- Convenient online submission

- Rigorous peer review

- Open access: articles freely available online

- High visibility within the field

- Retaining the copyright to your article

Submit your next manuscript at $\boldsymbol{\nabla}$ springeropen.com 